\title{
Tailoring of porous texture of hemp stem-based activated carbon produced by phosphoric acid activation in steam atmosphere
}

\author{
Iwona Lupul · Jan Yperman • Robert Carleer • \\ Grażyna Gryglewicz
}

Published online: 12 December 2014

(C) The Author(s) 2014. This article is published with open access at Springerlink.com

\begin{abstract}
A series of activated carbons (ACs) were produced by chemical activation of hemp stem with phosphoric acid in nitrogen and steam atmospheres. The potential of hemp-derived waste for the manufacture of porous carbons with a wide spectrum of porosity, ranging from microporous to mesoporous, has been demonstrated. The influence of the variables, such as the $\mathrm{H}_{3} \mathrm{PO}_{4}$ /hemp stem impregnation ratio, the soaking time and the gaseous atmosphere, on the porosity development was studied. Depending on the processing conditions, the $\mathrm{H}_{3} \mathrm{PO}_{4}$ activation produces ACs with a wide range of textural parameters, reaching surface areas $>2,500 \mathrm{~m}^{2} / \mathrm{g}$, micropore pore volumes up to $0.89 \mathrm{~cm}^{3} / \mathrm{g}$ and mesopore volumes up to $1.80 \mathrm{~cm}^{3} / \mathrm{g}$. The amount of $\mathrm{H}_{3} \mathrm{PO}_{4}$ used in the impregnation step affects the porous texture of the resultant ACs to a greater extent than the soaking time. At low and medium impregnation ratios, a steam atmosphere favors the formation of mesopores during $\mathrm{H}_{3} \mathrm{PO}_{4}$ activation.
\end{abstract}

Keywords Hemp stem - Activated carbon - Phosphoric acid activation - Porous structure

I. Lupul · G. Gryglewicz $(\bowtie)$

Department of Polymer and Carbonaceous Materials, Faculty of Chemistry, Wrocław University of Technology, Gdańska 7/9, 50-344 Wrocław, Poland

e-mail: grazyna.gryglewicz@pwr.edu.pl

J. Yperman · R. Carleer

Research Group of Applied and Analytical Chemistry, CMK, Hasselt University, Agoralaan Gebouw D, 3590 Diepenbeek, Belgium

\section{Introduction}

Hemp (Cannabis sativa L.) is an annual and highly productive herbaceous plant. It has been widely cultivated in China, mainly for its bast fiber and seed oil [1]. The world cultivation of hemp occupies over 40,000 ha. Hemp has many industrial applications, including the production of paper, textiles, building materials, food, medicine, paint, detergents, oil and fuel. Therefore, a huge amount of waste and by-products such as hemp seed, hemp bast and hemp stem are generated during hemp processing. The production of hemp-derived waste was estimated to be approximately 54,000 tons in 2012. The preparation of activated carbons (ACs) from hemp stem waste as a precursor can be considered an attractive alternative to its disposal.

ACs are widely used on an industrial scale as adsorbents for the removal of contaminants from drinking water and wastewater, as well as for the purification and separation of gases, catalysts and catalyst supports [2]. The continuous development of this technology expands the potential applications of ACs in energy storage, e.g., in electrochemical capacitors [3] and for methane storage [4]. The performance efficiency of ACs in various applications is related to their developed surface area, favorable pore volume distribution and surface chemistry, including the amount and nature of the oxygen- and nitrogen-containing functional groups [5]. These features are determined by the physical and chemical properties of the precursor material and the AC preparation method [6].

ACs are produced by physical or chemical activation or a combination of these. Physical activation is a two-step method that includes carbonization and subsequent partial gasification with steam and $\mathrm{CO}_{2}$ at a high temperature $\left(800-1,000{ }^{\circ} \mathrm{C}\right)$. Chemical activation is conducted in one stage in the presence of reagents, such as $\mathrm{H}_{3} \mathrm{PO}_{4}, \mathrm{KOH}$, 
$\mathrm{NaOH}$ and $\mathrm{ZnCl}_{2}$, at a much lower temperature $\left(450-700{ }^{\circ} \mathrm{C}\right)$. The raw materials for the production of commercial ACs are wood, coal, lignite, peat and coconut shells. In recent years, numerous alternative lignocellulosic materials from agricultural wastes, such as fruit stones, nut shells, olive stone, corn cob, cotton stalks, bagasse or rice husk, coconut fibers and many others, have been used to produce low-cost ACs on a laboratory scale [7-14]. However, few reports exist on the preparation of ACs using hemp-derived materials [15-18].

Most commercially available ACs are microporous. They are produced mainly by physical activation using steam as the activating agent. A high contribution of both micropores and mesopores in the porous texture of the carbon was obtained by chemical activation of olive and peach stones with phosphoric acid [19]. The degree of the mesopore development depends mainly on the biopolymer composition of the precursor and the processing parameters [20]. The $\mathrm{H}_{3} \mathrm{PO}_{4}$-promoted activation of cellulose favors the formation of mesopores, whereas lignin is responsible for the development of micropores [21, 22]. The influence of the processing parameters, such as the impregnation ratio, activation temperature and soaking time, on the porosity development during $\mathrm{H}_{3} \mathrm{PO}_{4}$ activation of lignocellulosic precursors in an inert atmosphere has been extensively investigated [11, 14, 16, 17, 23-26]. However, a gaseous atmosphere can also considerably influence the porous texture of the resultant ACs. It was reported that the $\mathrm{H}_{3} \mathrm{PO}_{4}$-promoted activation of wood under steam flow results in a product with improved development of the mesoporous structure compared with activation under nitrogen flow [27-29].

The aim of this work is to compare the porosity development in hemp stem-based ACs prepared by $\mathrm{H}_{3} \mathrm{PO}_{4}$ activation under steam and nitrogen flow. The influence of the processing variables, such as the $\mathrm{H}_{3} \mathrm{PO}_{4}$ /precursor ratio and the soaking time at $480{ }^{\circ} \mathrm{C}$, on the porous structure of the resultant ACs was investigated. The porosity development during $\mathrm{H}_{3} \mathrm{PO}_{4}$ activation of hemp stem waste in a steam atmosphere has never before been discussed in the literature.

\section{Methods}

\subsection{Materials}

Dry hemp (C. sativa L.) stems were used in the preparation of ACs. Prior to use, the hemp stems were cleaned of leaves, cut in fractions of approximately $5 \mathrm{~mm}$ and kept at room temperature. The prepared samples were impregnated with $\mathrm{H}_{3} \mathrm{PO}_{4}$ solutions of three different concentrations, i.e., 10, 30 and $50 \%$, which corresponds to an impregnation ratio $\left(X_{P}\right)$ of $0.16,0.52$ and 0.99 , respectively. The $X_{P}$ was defined as grams of phosphorous per grams of dry hemp stems. To ensure the access of $\mathrm{H}_{3} \mathrm{PO}_{4}$ to the interior of the hemp stem, the soaked samples were left for $24 \mathrm{~h}$ at room temperature and then dried in an oven at $110^{\circ} \mathrm{C}$ for $4 \mathrm{~h}$. Subsequently, the samples were subjected to heat treatment at $200{ }^{\circ} \mathrm{C}$ for $10 \mathrm{~min}$, resulting in a black plastic form.

\subsection{Activation}

The impregnated samples were placed in a vertical furnace and heated to $480{ }^{\circ} \mathrm{C}$ at $1^{\circ} \mathrm{C} / \mathrm{min}$ in flowing nitrogen $\left(330 \mathrm{~cm}^{3} / \mathrm{min}\right)$. The soaking time at the final temperature varied from 10 to $60 \mathrm{~min}$. For activation in a steam atmosphere, steam $\left(1.5 \mathrm{~cm}^{3} / \mathrm{min}\right)$ was introduced with nitrogen as a carrier gas when the temperature reached $300{ }^{\circ} \mathrm{C}$, and then heat treatment was continued to $480{ }^{\circ} \mathrm{C}$ at $1{ }^{\circ} \mathrm{C} / \mathrm{min}$ with a different soaking time. The activated products were cooled to room temperature under nitrogen flow and subsequently washed with hot distilled water until reaching a neutral $\mathrm{pH}$. Finally, the resultant ACs were dried at $110^{\circ} \mathrm{C}$ and stored in a desiccator.

The ACs were labeled as $\mathrm{AH}$ followed by numbers indicating the impregnation ratio and soaking time and by letters corresponding to steam $(\mathrm{S})$ and nitrogen $(\mathrm{N})$ atmospheres. For example, AH/0.99/60S refers to the AC produced from hemp stems impregnated at $X_{P}=0.99$ and subsequently activated under steam at $480{ }^{\circ} \mathrm{C}$ with a 60 min soaking time.

\subsection{Analyses}

The biopolymer composition of the hemp stem was determined according the Polish Standard PN-92/P-50092. The elemental analysis of $\mathrm{C}, \mathrm{H}$ and $\mathrm{N}$ was performed using a Vario III elemental analyzer. The oxygen content was calculated by difference. The porous structure parameters were determined from nitrogen adsorption isotherms measured at $77 \mathrm{~K}$ using a NOVA 2200 gas sorption analyzer (Quantachrome). Prior to the measurements, the sample was outgassed overnight at $300{ }^{\circ} \mathrm{C}$. The specific surface area $\left(\mathrm{S}_{\mathrm{BET}}\right)$ was calculated using the BrunauerEmmett-Teller (BET) equation. The amount of nitrogen adsorbed at the relatively pressure of $\mathrm{p} / \mathrm{p}_{0}=0.96$ was employed to determine the total pore volume $\left(\mathrm{V}_{\mathrm{T}}\right)$. The micropore volume $\left(\mathrm{V}_{\mathrm{DR}}\right)$ was determined by applying the Dubinin-Radushkevich equation. The mesopore volume $\left(\mathrm{V}_{\text {mes }}\right)$ was calculated as the difference between $\mathrm{V}_{\mathrm{T}}$ and $\mathrm{V}_{\mathrm{DR}}$. The mesopore fraction was expressed as the ratio of the mesopore volume to the total pore volume. The quenched solid density functional theory (QSDFT) was used to obtain the pore volume distribution [30]. 


\section{Results and discussion}

\subsection{Characterization of the raw material}

The characteristics of the hemp stem used in this study are given in Table 1 . The analysis of the biopolymer composition revealed that the hemp stem contains a considerably larger amount of cellulose than hemicellulose and lignin. Cellulose constitutes more than half of the hemp composition, i.e., much greater than that of wood, which accounts for the fibrous nature of the material. The ash content in the hemp stem is low (1.8 wt\%).

\subsection{Influence of the impregnation ratio on the porosity development in a steam atmosphere}

The evolution of the porous structure with an increasing impregnation ratio was studied for ACs obtained at $480{ }^{\circ} \mathrm{C}$ in a steam atmosphere with a soaking time of $30 \mathrm{~min}$. Figure 1 shows $\mathrm{N}_{2}$ sorption isotherms at $77 \mathrm{~K}$ for $\mathrm{ACs}$ prepared with different amounts of $\mathrm{H}_{3} \mathrm{PO}_{4}$. The isotherm of the hemp stem impregnated at $X_{P}=0.16$ represents a typical Type I isotherm according to the IUPAC classification [31]. A significant increase of the $\mathrm{N}_{2}$ adsorption at a very low relative pressure $(<0.1)$ and a long plateau, which extends to $\mathrm{p} / \mathrm{p}_{0} \sim 0.98$, indicates that $\mathrm{AH} / 0.16 / 30 \mathrm{~S}$ is mostly microporous. As the $X_{P}$ is increased to 0.52 , the slope of the isotherm gradually increases and a large hysteresis can be observed. The isotherm appears to be a combination of Types I and IV, indicating a high contribution of both micropores and mesopores. A further increase of the $X_{P}$ to 0.99 results in a decrease hysteresis loop shifted toward the higher values of relative pressure, which was followed by a decrease in the $\mathrm{N}_{2}$ adsorption related to micropores. The changes in the textural parameters of the ACs, calculated from the $\mathrm{N}_{2}$ adsorption at $77 \mathrm{~K}$, induced by different amounts of $\mathrm{H}_{3} \mathrm{PO}_{4}$ are shown in Fig. 2.

The BET surface area and the total pore volume increase with increasing impregnation ratio and attain maximum of $2,560 \mathrm{~m}^{2} / \mathrm{g}$ and $2.12 \mathrm{~cm}^{3} / \mathrm{g}$, respectively, for $X_{P}=0.52$. The mesopore and micropore volumes follow a similar trend. A very high mesopore volume $\left(1.23 \mathrm{~cm}^{3} / \mathrm{g}\right)$ was obtained. At a higher $\mathrm{X}_{\mathrm{P}}(0.99)$, a substantial decrease of $\mathrm{S}_{\mathrm{BET}}$ and $\mathrm{V}_{\mathrm{T}}$ is observed $\left(920 \mathrm{~m}^{2} / \mathrm{g}\right.$ and $0.940 \mathrm{~cm}^{3} / \mathrm{g}$, respectively). A different trend of porosity development

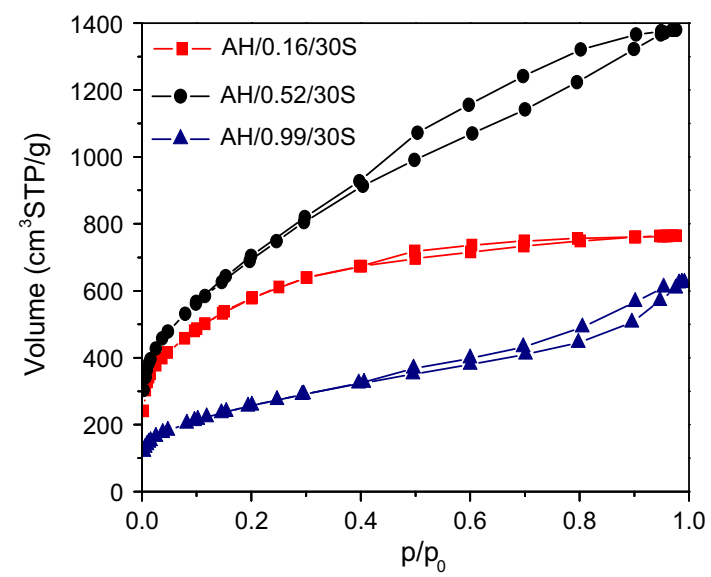

Fig. $1 \mathrm{~N}_{2}$ adsorption-desorption isotherms at $77 \mathrm{~K}$ for ACs prepared by phosphoric acid activation of hemp stem at different impregnation ratios

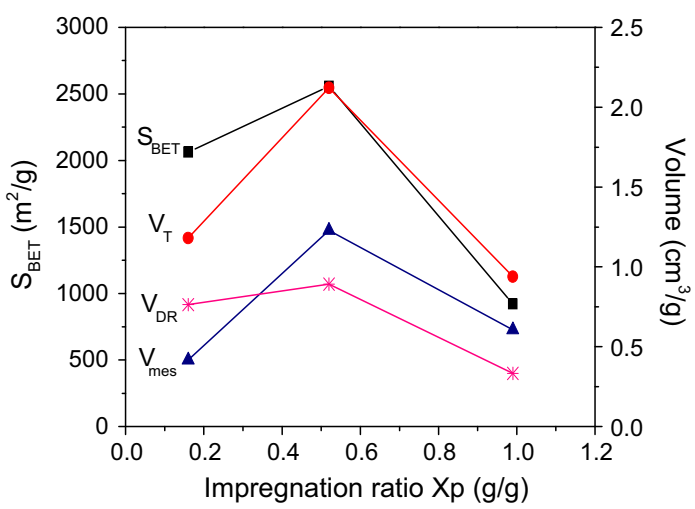

Fig. 2 Variations in the BET surface areas and pore volumes as a function of the impregnation ratio for ACs prepared by phosphoric acid activation of hemp stem in a steam atmosphere

during $\mathrm{H}_{3} \mathrm{PO}_{4}$ activation in a steam atmosphere was reported for oak, for which the maximum occurred at $\mathrm{X}_{\mathrm{P}}=0.99$ [27]. This result can be attributed to a lower content of cellulose in oak than in hemp stem (39.4 vs. $51.4 \mathrm{wt} \%)$. The obtained results are consistent with the fact that cellulose promotes the development of wider pores [21, 22].

Figure 3 shows the pore volume distribution determined using the QSDFT for hemp stem-based ACs prepared in a steam atmosphere using different impregnation ratios.

At a low $\mathrm{X}_{\mathrm{P}}$, phosphoric acid promotes the development of microporosity, yielding a $65 \%$ contribution of
Table 1 Composition of hemp stem used as a precursor for $\mathrm{AC}$ preparation, wt $\%$

\begin{tabular}{|c|c|c|c|c|c|c|c|c|}
\hline \multicolumn{2}{|c|}{ Proximate analysis } & \multicolumn{4}{|c|}{ Ultimate analysis (db) } & \multicolumn{3}{|c|}{ Biopolymer content } \\
\hline Moisture & Ash & $\mathrm{C}$ & $\mathrm{H}$ & $\mathrm{N}$ & $\mathrm{O}$ & Cellulose & Hemicellulose & Lignin \\
\hline 15.7 & 1.8 & 48.4 & 6.4 & 0.3 & 44.9 & 51.4 & 20.2 & 13.2 \\
\hline
\end{tabular}




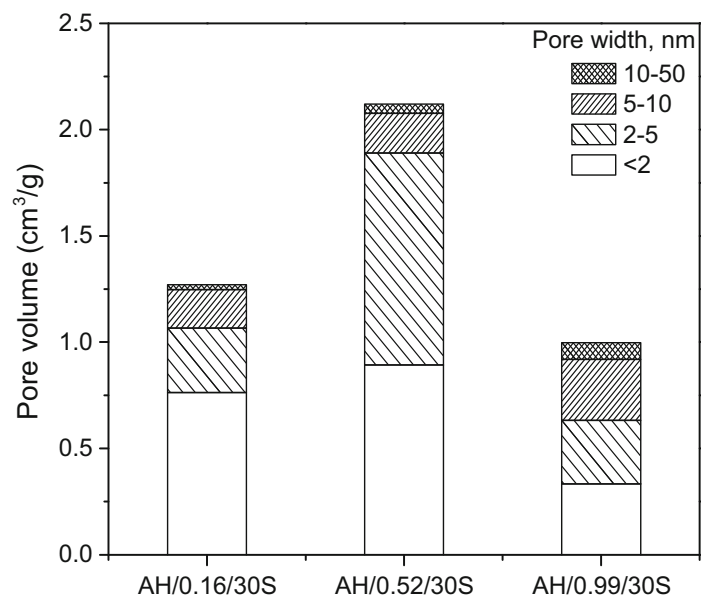

Fig. 3 Influence of the impregnation ratio on the pore volume distribution for hemp stem-based ACs produced by phosphoric acid activation in a steam atmosphere

micropores to the total pore volume of the resultant AC. This finding was also observed during heat treatment in an inert atmosphere $[17,32,33]$. As the $X_{P}$ increases to 0.52 , mesoporosity is preferentially developed whereas the microporosity hardly changes. The increase of the mesopore fraction is due to the enhanced formation of mesopores between 2 and $5 \mathrm{~nm}$. As a result, the narrow mesopores with a width of $2-10 \mathrm{~nm}$ constitute $>96 \%$ of the total mesopore volume for $\mathrm{AH} / 0.52 / 30 \mathrm{~S}$. This carbon appears to be a very promising catalyst support candidate due to the abundance of narrow mesopores. Further increasing amount of the activating agent results in a significant reduction in the volumes of the micropores and the formation of narrow mesopores, which is accompanied by a reasonable increase in the volume of large mesopores (between 10 and $50 \mathrm{~nm}$ ). Following a fundamental paper by Jagtoyen and Derbyshire [34], $\mathrm{H}_{3} \mathrm{PO}_{4}$ promotes bond cleavage reactions in the biopolymer constituents and the formation of crosslinks via cyclization and condensation, which finally leads to phosphate and polyphosphate bridges combining biopolymer fragments. The formation of these linkages expands the biomass structure and delivers porosity. A greater amount of $\mathrm{H}_{3} \mathrm{PO}_{4}$ provides a much greater dilation of the porous structure. However, an excess of the activating agent results in a decrease in porosity, as observed for $\mathrm{X}_{\mathrm{P}}=0.99$, due to a collapse of the existing pores.

In summary, $X_{P}=0.52$ at a 30 min soaking time allows for the production of an $\mathrm{AC}$ with the greatest volume of both micropores and mesopores, i.e., 0.89 and $1.23 \mathrm{~cm}^{3} / \mathrm{g}$, respectively. Therefore, this impregnation ratio was selected for a further study to determine the effect of soaking time on the porous texture of hemp stem-based ACs.
3.3 Influence of the soaking time on the porosity development in steam atmosphere

Figure 4 shows the $\mathrm{N}_{2}$ adsorption-desorption isotherms at $77 \mathrm{~K}$ for ACs prepared by impregnation at $\mathrm{X}_{\mathrm{P}}=0.52$ and activated at $480{ }^{\circ} \mathrm{C}$ with different soaking times $(10,30$, $60 \mathrm{~min}$ ) in a steam atmosphere.

The resultant ACs are characterized by a wide hysteresis loop, which suggests a large portion of mesopores in their porous structure. Figure 5 shows the changes in the porous structure of the ACs as a function of the soaking time. As the soaking time increases from 10 to $30 \mathrm{~min}$, the $\mathrm{S}_{\mathrm{BET}}$ increases from 2,074 to $2,560 \mathrm{~m}^{2} / \mathrm{g}$ and then drastically decreases to $1,580 \mathrm{~m}^{2} / \mathrm{g}$ at a soaking time of $60 \mathrm{~min}$. The maximum in the evolution of the microporosity and mesoporosity was also reached at a soaking time of $30 \mathrm{~min}$. A destructive influence of longer soaking time $(60 \mathrm{~min})$ on the development of the porosity is confirmed by the pore volume distribution (Fig. 6). In contrast, a short soaking time $(10 \mathrm{~min})$ results in an under developed porosity. A progressive enlargement of existing pores with increasing activation time followed by their collapse is responsible for the decay in the porosity development. For a soaking time of 10-30 $\mathrm{min}$, the changes in the pore volume distribution are mainly related to the evolution of micropores and mesopores with a width of $2-5 \mathrm{~nm}$. An extension of the soaking time to $60 \mathrm{~min}$ leads to a considerable decrease in the micropore volume followed by an increase of wider mesopores that have a width of 5-50 $\mathrm{nm}$. Comparing the pore volume distributions shown in Figs. 3 and 6, the soaking time has a weaker influence on the evolution of micro- and mesoporosity than the impregnation ratio. This finding is consistent with results reported using other lignocellulosic precursors activated with $\mathrm{H}_{3} \mathrm{PO}_{4}$ in an inert atmosphere [23, 24].

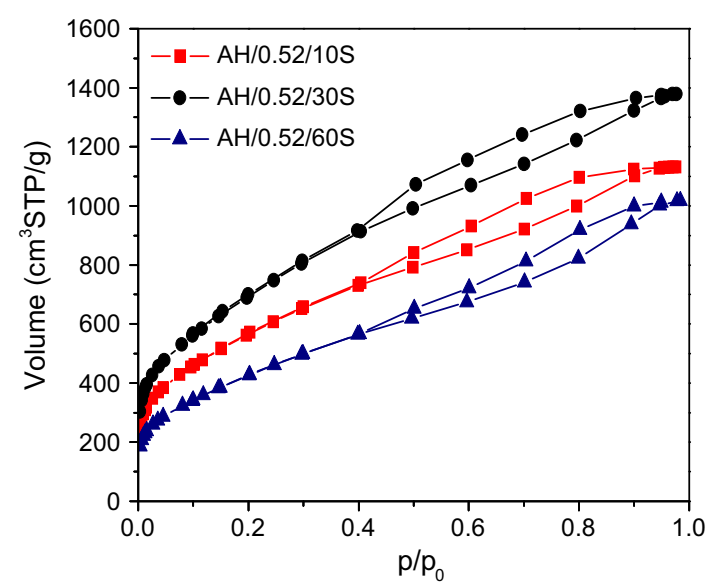

Fig. $4 \mathrm{~N}_{2}$ adsorption-desorption isotherms at $77 \mathrm{~K}$ for ACs prepared by phosphoric acid activation of hemp stem with different soaking times 


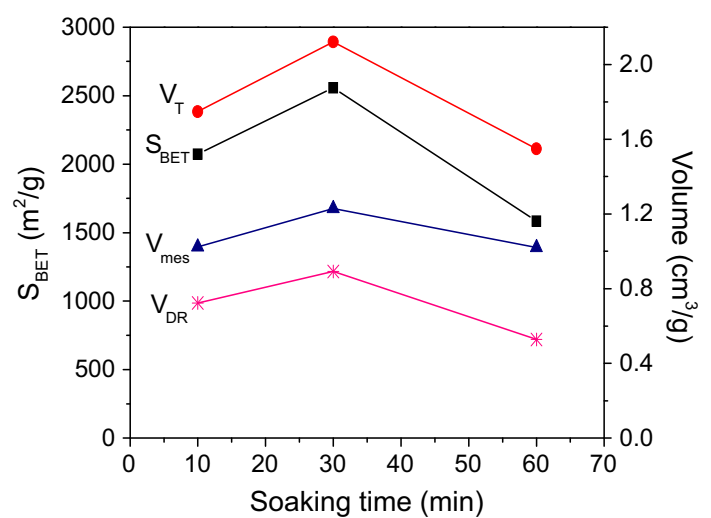

Fig. 5 Variations in the BET surface areas and pore volumes as a function of the soaking time for ACs prepared by phosphoric acid activation of hemp stem at $X_{P}=0.52$ in a steam atmosphere

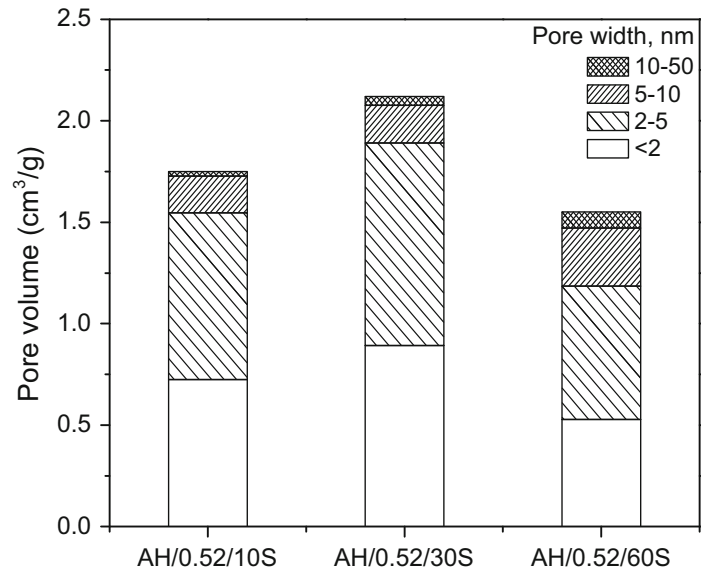

Fig. 6 Influence of the soaking time on the pore volume distribution for hemp stem-based ACs produced by phosphoric acid activation in a steam atmosphere

Notably, a high mesopore ratio of the resultant ACs, up to 0.64 , is related to the high contribution of cellulose in the composition of the hemp stem (Table 1). The linkages formed between cellulose and $\mathrm{H}_{3} \mathrm{PO}_{4}$ during heat treatment promotes cross-linking and dilation of the structure whereas lignin shows a significantly lower potential for expansion $[20,34]$. Removal of the phosphorus-containing compounds by washing after the activation process has a decisive impact on the porous structure of the resultant AC. Taking into account that steam, in contrast with nitrogen, favors elimination of phosphate groups during the activation process [28], the porosity development in the hemp stem-based ACs obtained in both atmospheres has been compared.

\subsection{Influence of a gaseous atmosphere on the porosity} development during $\mathrm{H}_{3} \mathrm{PO}_{4}$ activation

Figure 7 shows the pore volume distribution for ACs prepared in steam and nitrogen atmospheres at different impregnation ratios and soaking times. For $X_{P}=0.16$ the resultant ACs are microporous regardless of the type of atmosphere (Fig. 7a). If steam was applied, a reasonable decrease in the micropore volume, from 0.92 to $0.60 \mathrm{~cm}^{3} /$ $\mathrm{g}$, can be observed with increasing soaking time, whereas the mesopore volume remains almost unchanged. This result is accompanied by a decrease in the BET surface area from 2,400 to $1,600 \mathrm{~m}^{2} / \mathrm{g}$. In the nitrogen atmosphere, the micropore and mesopore volumes slightly increase with the soaking time. For $X_{P}=0.52$, the total pore volume of the ACs obtained in the steam and nitrogen atmospheres is comparable for a given soaking time (Fig. 7b). However, the contribution of mesopores is reasonably higher for the ACs prepared under a steam flow. For $X_{P}=0.99$, a different tendency of the porosity evolution can be observed for both atmospheres (Fig. 7c). The ACs produced under
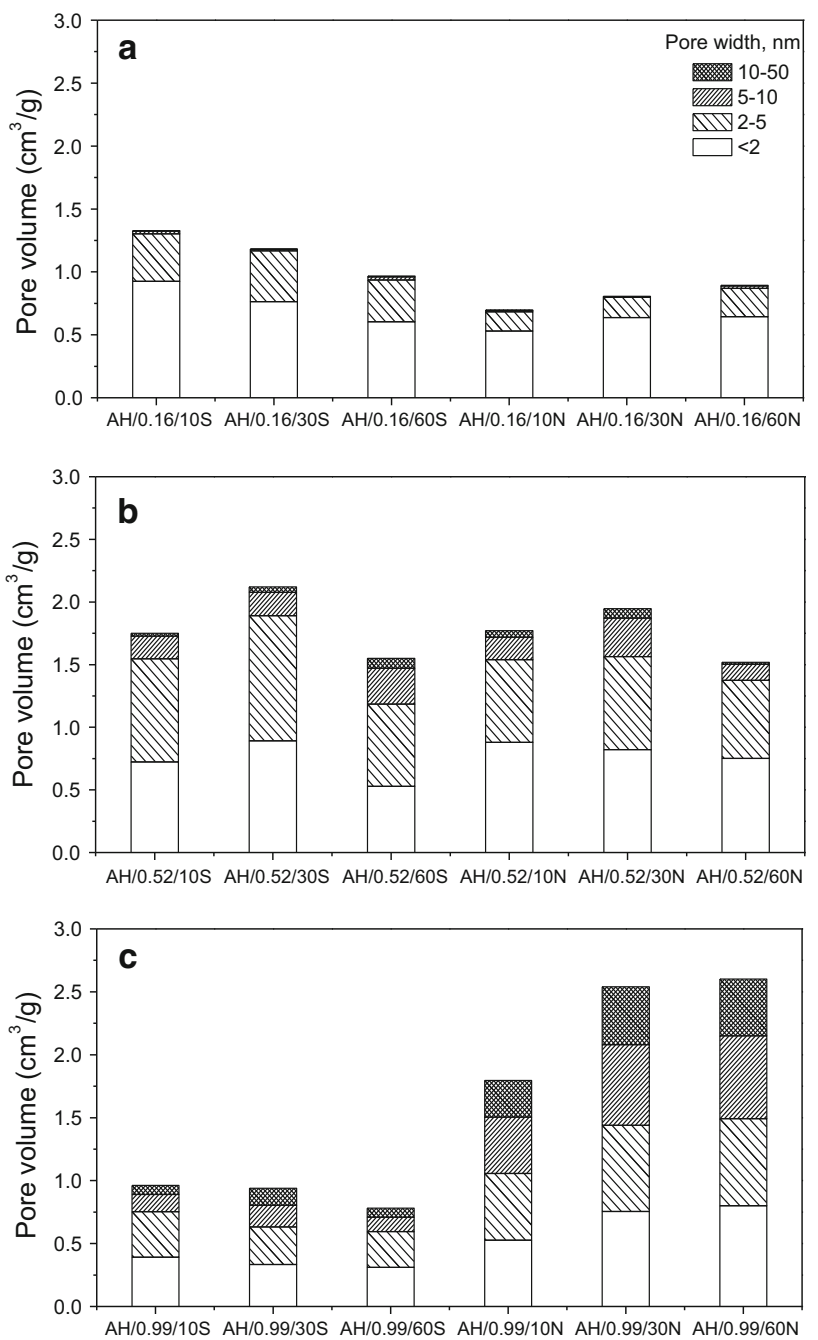

Fig. 7 Comparison of the pore volume distribution of hemp stembased ACs prepared by $\mathrm{H}_{3} \mathrm{PO}_{4}$ activation in steam and nitrogen atmospheres at different impregnation ratios $\mathrm{X}_{\mathrm{P}}=0.16$ (a), 0.52 (b) and 0.99 (c) 
nitrogen flow show improved development of the porous texture than those obtained in the steam atmosphere. This finding can be explained by the excess of activating agent used, leading to a very large dilatation. The extremely extended structure is weak, and the existing pores collapse as a result of the enhanced elimination of phosphate compounds during $\mathrm{H}_{3} \mathrm{PO}_{4}$ activation under a steam flow, which do not occur with nitrogen. Therefore, an extremely high the total pore volume (above $2.5 \mathrm{~cm}^{3} / \mathrm{g}$ ) and mesopore volume $\left(1.8 \mathrm{~cm}^{3} / \mathrm{g}\right)$ was reached during $\mathrm{H}_{3} \mathrm{PO}_{4}$ in a nitrogen atmosphere $X_{P}=0.99$ with a 60 min soaking time. These values are superior to those for other $\mathrm{H}_{3} \mathrm{PO}_{4}$-promoted ACs reported in the literature. Figure 7 also shows that, for both steam and nitrogen atmospheres, a low impregnation ratio favors the evolution of narrow mesopores with a width $<5 \mathrm{~nm}$, whereas mesopores with a width of $5-50 \mathrm{~nm}$ are preferentially developed at a high impregnation ratio.

It should be added that the yield of activation of hemp stem using phosphoric acid is relatively low. It decreases from 21 to $18 \mathrm{wt} \%$ for nitrogen atmosphere and from 18 to $13 \mathrm{wt} \%$ for steam atmosphere with an increase in the impregnation ratio. The low yield is related to the group composition of hemp stem, which is abundant in cellulose (Table 1). Research on the activation of individual biomass components, i.e., lignin, cellulose and hemicellulose, with phosphoric acid has revealed that the lowest yield of the process is obtained for cellulose [21].

This study has shown that an appropriate selection of the processing variables for $\mathrm{H}_{3} \mathrm{PO}_{4}$ activation provides large possibilities for producing ACs of desired textural parameters using hemp stem waste as a precursor. The selected hemp stem-derived ACs are now being studied as adsorbents for water treatment and as catalyst supports for hydrogenation in the liquid phase.

\section{Conclusions}

An outstanding potential of hemp stem for the manufacture of porous carbons with a wide spectrum of porosity, ranging from microporous to mesoporous, has been presented. The amount of phosphoric acid, the soaking time and the gaseous atmosphere, allows for control of the porous structure in hemp stem-based ACs obtained by $\mathrm{H}_{3} \mathrm{PO}_{4}$ activation. Among these variables, the impregnation ratio affects the porosity development to the highest extent. The impregnation of hemp stem with a low amount of $\mathrm{H}_{3} \mathrm{PO}_{4}\left(\mathrm{X}_{\mathrm{P}}=0.16\right)$ promotes the evolution of micropores in both steam and nitrogen flows. At $X_{P}=0.52$ the $\mathrm{AC}$ with the highest surface area $\left(2,560 \mathrm{~m}^{2} / \mathrm{g}\right)$ and well developed meso- and microporosity $\left(\mathrm{V}_{\text {mes }}=1.23 \mathrm{~cm}^{3} / \mathrm{g}\right.$, $\mathrm{V}_{\text {mic }}=0.89 \mathrm{~cm}^{3} / \mathrm{g}$ ) is produced in a steam atmosphere with a soaking time of $30 \mathrm{~min}$. Both a high impregnation ratio $\left(X_{P}=0.99\right)$ and a long soaking time $(60 \mathrm{~min})$ result in porosity degradation when the activation is performed in a steam atmosphere. In contrast, the use of nitrogen in the same conditions leads to increased porosity development. The total pore volume and mesopore volume reach impressively high values, 2.6 and $1.8 \mathrm{~cm}^{3} / \mathrm{g}$, respectively. The obtained results prove that hemp stem waste can be successfully used for the production of ACs with a wide porosity spectrum by $\mathrm{H}_{3} \mathrm{PO}_{4}$ activation.

Acknowledgments This work was financed by a statutory activity subsidy from the Polish Ministry of Science and Higher Education for the Faculty of Chemistry of Wrocław University of Technology.

Open Access This article is distributed under the terms of the Creative Commons Attribution License which permits any use, distribution, and reproduction in any medium, provided the original author(s) and the source are credited.

\section{References}

1. B.D. OOmah, M. Busson, D.V. Godfrey, J.C. Drover, Food Chem. 76, 33 (2002)

2. H. Marsh, F. Rodríguez-Reinoso, Activated Carbon (Elsevier, Amsterdam, 2006)

3. M. Inagaki, H. Konno, O. Tanaike, J. Power Sources 195, 7880 (2010)

4. J. Alcañiz-Monge, D. Lozano-Castelló, D. Cazorla-Amorós, A. Linares-Solano, Micropor. Mesopor. Mater. 124, 110 (2009)

5. L.R. Radovic, C. Moreno-Castilla, J. Rivera-Utrilla, in Chemistry and Physics of Carbon, vol. 27, ed. by P.A. Thrower (Marcel Dekker, New York, 2001), pp. 228-405

6. F. Rodríguez-Reinoso, in Introduction to Carbon Technologies, ed. by H. Marsh, E.A. Heintz, F. Rodríguez-Reinoso (Universidad, Alicante, 1997), pp. 35-103

7. N.M. Haimour, S. Emeish, Waste Manage. 28, 651 (2006)

8. E. Yagmur, J. Porous Mater. 19, 995 (2012)

9. J. Guo, A.C. Lua, J. Porous Mater. 7, 491 (2000)

10. W.T. Tsai, C.Y. Chang, S.Y. Wang, C.F. Chang, S.F. Chein, H.F. Sun, Ind. Crops Prod. 23, 23 (2001)

11. M. Anas Nahil, P.T. Williams, Biomass Bioenergy 37, 142 (2012)

12. A.J. Romero-Anaya, M.A. Lillo-Rodenas, C. Salinas-Martinez de Lecea, A. Linares-Solano, Carbon 50, 3158 (2012)

13. D. Kalderis, S. Bethanis, P. Paraskeva, E. Diamadopoulos, Bioresour. Technol. 99, 6809 (2008)

14. S.-L. Liu, Y.-N. Wang, K.-T. Lu, J. Porous Mater. 21, 459 (2014)

15. P.T. Williams, A.R. Reed, J. Anal. Appl. Pyrol. 71, 971 (2004)

16. J.M. Rosas, J. Bedia, J. Rodríguez-Mirasol, T. Cordero, Fuel 88, 19 (2009)

17. R. Yang, G. Liu, X. Xu, M. Li, J. Zhang, X. Hao, Biomass Bioenergy 35, 437 (2010)

18. R. Yang, G. Liu, M. Li, J. Zhang, X. Hao, Micropor. Mesopor. Mater. 158, 108 (2012)

19. M. Molina-Sabio, F. Rodríguez-Reinoso, Colloids Surf. A 241, $15(2004)$

20. M.S. Solum, R.J. Pugmire, M. Jagtoyen, F. Derbyshire, Carbon 33, 1247 (1995)

21. B. Tiryaki, E. Yagmur, A. Banford, Z. Aktas, J. Anal. Appl. Pyrol. 105, 276 (2014) 
22. V. Fierro, V. Torné-Fernández, A. Celzard, Micropor. Mesopor. Mater. 92, 243 (2006)

23. Y. Guo, D.A. Rockstraw, Bioresour. Technol. 98, 1513 (2007)

24. V. Fierro, G. Muñiz, A.H. Basta, H. El-Saied, A. Celzard, J. Hazard. Mater. 181, 27 (2010)

25. Y. Diao, W.P. Walawender, L.T. Fan, Bioresour. Technol. 81, 45 (2002)

26. Q.S. Liu, T. Zheng, P. Wang, L. Guo, Ind. Crops Prod. 31, 233 (2010)

27. A. Klijanienko, E. Lorenc-Grabowska, G. Gryglewicz, Bioresour. Technol. 99, 7208 (2008)

28. H. Benaddi, D. Legras, J.N. Rouzaud, F. Béguin, Carbon 36, 306 (1998)
29. H. Benaddi, T.J. Bandosz, J. Jagiełło, J.A. Schwarz, J.N. Rouzaud, D. Legras, F. Béguin, Carbon 38, 669 (2000)

30. A.V. Neimark, Y. Lin, P.I. Ravikovitch, M. Thommes, Carbon 47, 1617 (2009)

31. K.S.W. Sing, D.H. Everett, R.A.W. Haul, L. Moscou, R.A. Pierotti, J. Rouquérol, T. Siemieniewska, Pure Appl. Chem. 57, 603 (1985)

32. F. Suárez-García, A. Martínez-Alonso, J.M.D. Tascón, J. Anal. Appl. Pyrol. 63, 283 (2002)

33. P. Patnukao, P. Pavasant, Bioresour. Technol. 99, 8540 (2008)

34. M. Jagtoyen, F. Derbyshire, Carbon 36, 1085 (1998) 